\title{
Tinjauan Kelembagaan Dewan Pengawas Syariah dari Aspek Nomenklatur, Kedudukan di Lembaga Perbankan dan Remunerasi
}

\author{
Abdul Aziz \\ UIN Sunan Kalijaga Yogyakarta \\ abdulaziz45181@gmail.com
}

\begin{abstract}
DPS is a key institution that ensures the operational activities of sharia financial institutions are in accordance with sharia principles. In order to streamline the implementation of DPS duties, efforts are needed to increase knowledge of banking operations, as well as the intensity of its involvement in outreach programs for local residents. In practice, there are still many problems that cause the supervisory aspect not to be optimal as expected. This is caused by several factors, both internal and external. This study aims to determine the institutional review of DPS in terms of nomenclature, position in banking institutions and remuneration. The research method used in this research is literature review sourced from books, articles, internet and opinions of experts in accordance with the discussion. In according to the nomenclature, DPS in Indonesia would be more appropriate to use the term Sharia Advisory Board instead of the Sharia Supervisory Board. Meanwhile, in terms of position in banking institutions, DPS should only be allowed to serve in one financial institution so as not to create a conflict of interest between one financial institution and another. Whereas in terms of remuneration, it should be that which determines and provides remuneration to DPS is the association of sharia financial institutions such as the Association of Indonesian Sharia Banks (ASBISINDO), the Association of All Indonesian BMTs (ABSINDO), and others so as not to cause objectivity in implementation of duties because it will inevitably be biased in making decisions.
\end{abstract}

Keywords: Institutional, DPS, Islamic bank

\begin{abstract}
Abstrak
DPS merupakan lembaga kunci yang menjamin kegiatan operasional lembaga keuangan syariah sudah sesuai dengan prinsip-prinsip syariah. Dalam rangka mengefektifkan pelaksanaan tugas DPS diperlukan upaya peningkatan pengetahuan tentang operasional perbankan, serta intensitas keterlibatannya dalam program sosialisasi pada penduduk lokal. Dalam praktiknya, masih banyak ditemukan permasalahan yang menyebabkan tidak optimalnya aspek pengawasan sebagaimana yang diharapkan. Hal ini disebabkan oleh beberapa faktor baik internal maupun eksternal. Penelitian ini bertujuan untuk mengetahui tinjauan kelembagaan DPS dilihat dari aspek nomenklatur, kedudukan di lembaga perbankan dan remunerasi. Metode penelitian yang digunakan dalam penelitian ini adalah kajian pustaka yang bersumber dari buku, artikel, internet dan pendapat para ahli yang sesuai dengan pembahasan. Ditinjau dari nomenklatur, DPS di Indonesia akan lebih tepat jika menggunakan istilah Dewan Penasihat Syariah bukan Dewan Pengawas Syariah. Sementara ditinjau dari kedudukan di lembaga perbankan, seyogianya DPS hanya boleh
\end{abstract}


menjabat di satu lembaga keuangan saja agar tidak menimbulkan konflik kepentingan antara lembaga keuangan satu dengan yang lain. Sedangkan ditinjau dari remunerasi, seharusnya yang menentukan dan memberikan remunerasi kepada DPS adalah asosiasi lembaga keuangan syariah seperti Asosiasi Bank Syariah Indonesia (ASBISINDO), Asosiasi BMT Seluruh Indonesia (ABSINDO), dan lain-lain agar tidak menimbulkan ketidakobjektifan dalam pelaksanaan tugas karena pasti akan berat sebelah dalam mengambil keputusan.

Kata Kunci: Kelembagaan, DPS, bank syariah

\section{PENDAHULUAN}

Lembaga keuangan utamanya bank syariah memiliki beberapa keunikan dalam kaitannya antara nasabah deposan dengan bank syariah. Pertama, nasabah bank syariah berkeinginan agar seluruh penerimaan yang diperoleh dari bank syariah adalah halalan tayyiban. Keunikan selanjutnya, sebagai konsekuensi sistem bagi hasil, nasabah deposan disamping menerima return yang bersifat variatif berdasarkan realisasi laba rugi bank di masa mendatang, nasabah juga harus bersedia menanggung risiko kerugian yang sewaktu-waktu bisa terjadi.

Kedua keunikan inilah yang membedakan antara sistem pengelolaan bank syariah dengan bank konvensional. Pada bank konvensional, sistem pengelolaan yang baik dapat dikembangkan dengan memperjelas fungsi, kewenangan dan pola hubungan antara pemegang saham (dewan komisaris) dan pengurus bank. Sedangkan pada perbankan syariah, agar semua kepentingan para pihak dapat terpenuhi dengan baik, maka struktur pengelolaan dan pengawasan melibatkan empat pihak, yaitu pemegang saham (dewan komisaris), pengurus bank, Dewan Pengawas Syariah (DPS) dan/atau Dewan Syariah Nasional (DSN), serta nasabah deposan.

Masing-masing pihak memiliki kepentingan yang berbeda. Oleh karena itu, suatu sistem pengelolaan bank syariah yang baik mempersyaratkan adanya pengaturan yang jelas tentang batasan hak, kewenangan dan kewajiban dari setiap pihak terkait untuk menghindari terjadinya konflik kepentingan. Selain itu juga, agar tidak terjadi dominasi kepentingan salah satu pihak dengan mengabaikan kepentingan pihak lain serta pencapaian tujuan perusahaan yang hanya mengakomodasi beberapa pihak dan mengabaikan kepentingan pihak lain. (Mubarok, 2004). Dalam upaya memurnikan pelayanan institusi keuangan syariah agar benar-benar sejalan dengan ketentuan dan prinsip syariah, keberadaan DPS mutlak diperlukan. DPS merupakan lembaga kunci yang menjamin kegiatan operasional lembaga keuangan syariah sudah sesuai dengan prinsip-prinsip syariah. (Briefcase Book Eduksi Profesional Syariah, 2005). Dalam rangka mengefektifkan pelaksanaan tugas DPS diperlukan 
Tinjauan Kelembagaan Dewan Pengawas Syariah dari Aspek Nomenklatur, Kedudukan di Lembaga Perbankan dan Remunerasi

upaya peningkatan pengetahuan tentang operasional perbankan, serta intensitas keterlibatannya dalam program sosialisasi pada penduduk lokal (Absor, Hana, \& Nur, 2019).

Selain itu, lahirnya lembaga seperti DPS merupakan langkah maju dalam dunia keuangan di tanah air, terutama ketika terjadi moral hazard di kalangan praktisi keuangan, dimana mereka dengan seenaknya berbuat curang, menipu dan membungakan uang yang tidak hanya berakibat pada krisis keuangan semata, tetapi juga berakibat pada hilangnya trust dari masyarakat terhadap beberapa lembaga keuangan di Indonesia. Oleh karena itu, sebagai lembaga yang berkewajiban memastikan praktik lembaga keuangan syariah sesuai dengan prinsip-prinsip syariah, tentu tugas DPS merupakan tugas mulia dalam pandangan masyarakat dan terlebih di hadapan Allah.

Dalam praktiknya, masih banyak ditemukan permasalahan yang menyebabkan tidak optimalnya aspek pengawasan sebagaimana yang diharapkan. Hal ini disebabkan oleh beberapa faktor baik internal maupun eksternal. Faktor internal seperti terbatas dan lemahnya sumber daya manusia (SDM) yang memiliki pengetahuan qualified pada bidangnya, dan tidak tersedianya sarana dan prasarana untuk menunjang kelancaran tugas pengawasan yang memadai. Faktor eksternal seperti kurang atau tidak adanya dasar hukum pengawasan yang jelas dan tidak adanya organisasi dan manajemen pengawasan yang baik. Adanya problem pada aspek ini dapat berakibat fatal. Usaha lembaga bisnis berlabel syariah beroperasi tidak sesuai syariah. Ini berdampak pada munculnya ketidakpercayaan masyarakat terhadap lembaga-lembaga bisnis berlabel syariah secara keseluruhan. Salah satu kasus yang mencoreng nama baik perbankan syariah terjadi pada Bank Syariah Mandiri (BSM) cabang Bogor yang melakukan penyimpangan pemberian fasilitas pembiayaan kredit terhadap 197 nasabah fiktif senilai 102 miliar, dan merugikan bank yang bersangkutan hingga mencapai nominal 59 milyar (Tempo, 2013). Kasus ini melibatkan pegawai bank yang salah satu penyebabnya adalah lemahnya model pengawasan DPS yang berjalan selama ini. Berdasarkan hal di atas, penelitian ini ditujukan untuk mengupas sekelumit tentang kelembagaan DPS serta mencoba menganalisa efektivitas tugas DPS terhadap lembaga keuangan syariah di Indonesia.

\section{KAJIAN LITERATUR}

\section{Dewan Pengawas Syariah}

Dewan Pengawas Syariah (DPS) adalah ahli syariah yang diangkat oleh Rapat Umum Pemegang Saham (RUPS) atas rekomendasi Majelis Ulama Indonesia (MUI), dengan tugas memberikan nasihat dan saran kepada Tawazun: Journal of Sharia Economic Law Vol. 4 No.1 2021 
direksi serta mengawasi kegiatan perusahaan agar sesuai dengan prinsip syariah. DPS biasanya diletakkan pada posisi setingkat Dewan Komisaris pada setiap bank. Hal ini untuk menjamin efektivitas dari setiap opini yang diberikan oleh DPS (Absor et al., 2019). Oleh karena itu, biasanya penetapan anggota DPS dilakukan oleh Rapat Umum Pemegang Saham (RUPS), setelah para anggota DPS itu mendapat rekomendasi dari Dewan Syariah Nasional. Dari sinilah kita bisa tahu bahwa perbedaaan lembaga keuangan syariah dengan lembaga keuangan non syariah adalah adanya DPS pada setiap lembaga tersebut. Jumlah DPS di setiap lembaga keuangan adalah sebanyak tiga orang (Djazuli \& Janwari, 2002).

\section{Tugas, Wewenang dan Mekanisme DPS}

Merujuk pada surat keputusan Dewan Syariah Nasional No. 3 Tahun 2000, bahwa Dewan Pengawas Syariah (DPS) adalah bagian dari lembaga keuangan syariah yang bersangkutan, yang penempatannya atas persetujuan Dewan Syariah Nasional (DSN). DPS bertugas mengawasi pelaksanaan keputusan DSN di lembaga keuangan syariah. DPS diangkat dan diberhentikan oleh lembaga keuangan syariah melalui RUPS setelah mendapat rekomendasi dari DSN.

1. Tugas, Wewenang, Anggota, dan Independensi DPS

Tugas DPS adalah mendiskusikan masalah-masalah dan transaksitransaksi usaha yang dihadapkan kepadanya; dan ia menetapkan bahwa masalah atau transaksi itu sudah sesuai atau belum dengan prinsip syariah. Sedangkan wewenang DPS adalah (a) memberikan pedoman syariah kepada bank untuk pengerahan dana, penyaluran dana, dan kegiatan bank lainnya; dan (b) mengadakan perbaikan seandainya suatu produk yang dijalankan dinilai belum sesuai syariah.

Anggota DPS terdiri dari ahli syariah yang sedikit banyak menguasai hukum dagang yang berlaku dan terbiasa dengan kontrak-kontrak bisnis. Anggota DPS bersifat independen, dalam artian bahwa mereka tidak tunduk kepada pimpinan bank yang diawasinya. Dalam rangka menjamin independensi DPS, hal-hal yang perlu diperhatikan adalah (a) anggota DPS bukan staf bank; mereka tidak tunduk di bawah kekuasaan adminstratif bank; (b) mereka dipilih oleh Rapat Umum Pemegang Saham (RUPS); (c) honorarium mereka ditentukan oleh RUPS; dan (d) DPS mempunyai sistem kerja dan tugas-tugas tertentu seperti halnya badan pengawas lainnya. (Perwataatmadja \& Antonio, 1992).

2. Kedudukan DPS

Dalam buku yang diterbitkan oleh Bank Indonesia dijelaskan bahwa DPS mempunyai tiga kedudukan (Mubarok, 2004): 
Tinjauan Kelembagaan Dewan Pengawas Syariah dari Aspek Nomenklatur, Kedudukan di Lembaga Perbankan dan Remunerasi

a. Sebagai penasihat dan pemberi saran kepada direksi, pimpinan Unit Usaha Syariah, dan pimpinan kantor cabang syariah mengenai hal-hal yang berkaitan dengan aspek syariah.

b. Sebagai mediator antara bank dengan DSN dalam mengomunikasikan usul dan saran pengembangan produk dan

c. jasa bank yang memerlukan kajian dan fatwa dari DSN.

d. Sebagai perwakilan DSN yang ditempatkan pada bank. DPS wajib melaporkan kegiatan usaha dan perkembangan bank syariah yang diawasinya kepada DSN minimal satu kali dalam satu tahun.

3. Fungsi DPS

Fungsi Dewan Pengawas Syariah adalah sebagai berikut (Briefcase Book Eduksi Profesional Syariah, 2005):

a. DPS melakukan pengawasan secara periodik pada lembaga keuangan syariah yang berada di bawah pengawasannya.

b. DPS berkewajiban mengajukan usul-usul pengembangan lembaga keuangan syariah kepada pimpinan lembaga yang bersangkutan dan kepada DSN.

c. DPS melaporkan perkembangan produk dan operasional lembaga keuangan syariah yang diawasinya kepada DSN sekurangkurangnya dua kali dalam satu tahun anggaran.

d. DPS merumuskan permasalahan-permasalahan yang memerlukan pembahasan DSN.

4. Struktur DPS

Adapun struktur DPS adalah sebagai berikut:

a. Kedudukan DPS dalam struktur perusahaan berada setingkat dengan fungsi komisaris sebagai pengawas direksi.

b. Jika fungsi komisaris adalah pengawas dalam kaitannya dengan kinerja manajemen, maka DPS melakukan pengawasan kepada manajemen dalam kaitannya dengan implementasi sistem dan produk-produk agar tetap sesuai dengan syariah.

c. Bertanggung jawab atas pembinaan akhlak seluruh karyawan berdasarkan sistem pembinaan keislaman yang telah diprogramkan setiap tahunnya.

d. Ikut mengawasi pelanggaran nilai-nilai Islam di lingkungan perusahaan tersebut.

e. Bertanggung jawab atas seleksi syariah karyawan baru yang dilaksanakan oleh Biro Syariah.

\section{Efektivitas Peran DPS dalam Lembaga Keuangan Syariah}

Meskipun keberadaan DPS sebagai lembaga pengawas dalam lembaga keuangan syariah dijamin oleh Undang-Undang Nomor 10 tahun 1998, fungsi DPS belum berjalan secara optimal. Pada saat itu, yang lebih 
Tinjauan Kelembagaan Dewan Pengawas Syariah dari Aspek Nomenklatur, Kedudukan di Lembaga Perbankan dan Remunerasi

menonjol dalam memberikan teguran-teguran baik bersifat tertulis maupun lisan lebih banyak dilakukan oleh Biro Pengembangan Perbankan Syariah Bank Indonesia daripada DPS itu sendiri. Padahal, DPS mempunyai kewenangan untuk melaksanakan tugasnya sebagai badan pengawas syariah. Sebagai contoh, teguran tertulis dari Bank Indonesia tentang pelaksanaan akad murabahah. Pada fatwa DSN memang tidak disebutkan bahwa pelaksanaan akad murabahah antara bank dengan

Nasabahnya harus dilakukan dengan cara (setelah akad murabahah ditandatangani) bank yang membeli dan membayar (harga beli bank) langsung kepada pemasok yang kemudian setelah pemasok menyerahkan barangnya kepada nasabah, nasabah berhutang kepada bank sebesar harga jual bank sesuai akad.

Contoh lain yaitu tentang pengenaan denda kepada nasabah yang tidak melaksanakan kewajibannya membayar hutang pada waktunya sesuai akad. Memang pada Buku Kumpulan Fatwa DSN ada ketentuan tentang sanksi atas nasabah yang sebetulnya mampu membayar hutang tetapi menunda-nunda pembayaran. Sanksi tersebut hanya dapat dikenakan apabila memenuhi ketentuan-ketentuan bukan karena force majeur dan terbukti tidak beritikad baik.

Contoh-contoh di atas menurut Karena Perwataatmaja merupakan bukti dari belum adanya penjabaran secara teknis dari fatwa DSN, sehingga DPS tidak dapat melaksanakan tugasnya secara efektif dan efisien. Keputusan Dewan Syariah Nasional (DSN) mengenai petunjuk dan pelaksanaan penetapan anggota DPS pada lembaga keuangan syariah baru dikeluarkan pada tahun 2000. Dalam petunjuk dan pelaksanaan DPS sudah dicantumkan tugas, fungsi, dan wewenang DPS. Sehingga dengan surat keputusan tersebut DPS dapat melaksanakan tugasnya secara optimal, dan menjadikannya sebagai landasan operasional bagi seluruh lembaga keuangan syariah. Pada periode ini, DPS mempunyai peran utama yaitu sebagai lembaga fatwa. Efektivitas DPS dibuktikan dengan banyaknya fatwa yang diterbitkan oleh DPS Bank Muamalat.

Dewan Pengawas Syariah merupakan pakar ekonomi dan ulama yang menguasai bidang fiqh mu'amalah yang berdiri sendiri dan bertugas mengamati dan mengawasi operasional lembaga keuangan syariah dan produk-produknya agar sesuai dengan ketentuan-ketentuan syariat Islam, yaitu dengan mengawasi secara teliti bagaimana bentuk-bentuk perjanjian/akad yang dilaksanakan oleh lembaga keuangan syariah.

Dewan Pengawas Syariah (DPS) pada perbankan syariah dilakukan secara terbuka dan transparansi dengan melibatkan berbagai pihak yang independen, seperti pemilihan anggota KPU oleh tim yang independen atau pemilihan Hakim Agung oleh Komisi Yudisial. Dengan harapan agar orang yang terpilih sebagai anggota atau ketua Dewan Pengawas Syariah 
Tinjauan Kelembagaan Dewan Pengawas Syariah dari Aspek Nomenklatur, Kedudukan di Lembaga Perbankan dan Remunerasi

adalah orang mempunyai kemampuan di bidang syariah muamalah dan perbankan secara umum, sehingga mampu memberikan penilaian dan pengawasan secara maksimal pada system dan proses kerja perbankan.

Menurut Adiwarman Karim dalam Briefcase Book Edukasi Profesional Syariah, tidak mudah bertanggung jawab atas pengawasan syariah mengingat demikian kompleksnya permasalahan transaksi perbankan. Menimpakan beban berat ini hanya kepada DPS bukanlah cara yang realistis. Pengawasan syariah sepatutnya merupakan tanggung jawab bersama semua stakeholders. Selain DPS yang bertanggung jawab pada aspek syariahnya, aspek-aspek operasional pengawasan syariah paling tidak harus dilakukan oleh audit internal bank, direktur kepatuhan, bahkan komisaris pun harus ikut menjaga kepatuhan syariah. Audit eksternal yang dilakukan oleh kantor akuntan publik juga tidak boleh melewatkan begitu saja adanya pelanggaran atas kepatuhan syariah. Dan tentunya, Bank Indonesia ikut bertanggung jawab sebagai pemegang otoritas perbankan. Semua institusi ini sesuai kompetensi dan wewenangnya masing-masing harus bahu-membahu dalam menjalankan fungsi pengawasan syariah.

\section{METODE PENELITIAN}

Jenis penelitian yang digunakan dalam jurnal ini merupakan jenis penelitian kualitatif. Pendapat dari Moleong senada dengan Bogdan dan Taylor (1975), dimana mereka mengasumsikan bahwasanya penelitian kualitatif juga termasuk metodologi yang dimanfaatkan untuk prosedur penelitian yang menghasilkan data deskriptif. Data deskriptif adalah data yang ditulis menggunakan kata-kata secara mendetail. Penelitian ini bertujuan untuk mengetahui tinjauan kelembagaan DPS dilihat dari beberapa aspek, yaitu nomenklatur, kedudukan di lembaga perbankan dan remunerasi. Metode penelitian yang digunakan dalam penelitian ini adalah kajian pustaka (library research) yang bersumber dari buku, artikel, internet dan pendapat para ahli yang sesuai dengan pembahasan. Penelitian ini juga menggunakan referensi berupa teori yang relevan dengan permasalahan yang diteliti.

\section{PEMBAHASAN}

\section{Tinjauan Kelembagaan DPS berdasarkan Nomenklatur}

Kedudukan dan peran DPS dalam perbankan syariah dijelaskan dalam Undang-undang Perbankan Syariah Pasal 32 yang menegaskan bahwa DPS wajib dibentuk di Bank Umum Syariah dan Bank Umum Konvensional yang memiliki Unit Usaha Syariah. DPS sebagaimana dimaksud pada ayat 1 bertugas memberikan nasihat dan saran kepada direksi serta mengawasi kegiatan bank agar sesuai dengan prinsip 
syariah. Dalam pasal tersebut disebutkan terlebih dahulu tentang tugasnya untuk memberi nasihat dan saran, baru kemudian mengawasi. Tugas ini berlaku ketika bank dihadapkan pada pertanyaan mengenai apakah suatu aktivitasnya sesuai syariah atau tidak, serta dalam proses melakukan pengembangan produk yang akan disampaikan kepada DSN untuk memperoleh fatwa. Maka dari itu, nomenklatur DPS di Indonesia akan lebih tepat jika disebut sebagai Dewan Penasihat Syariah (Sharia Advisory Board atau Sharia Advisory Council) sebagaimana yang sudah diterapkan di Malaysia dan Pakistan, bukan Dewan Pengawas Syariah (Sharia Supervisory Board).

\section{Tinjauan Kelembagaan DPS berdasarkan Kedudukan di Lembaga} Perbankan

Secara yuridis, DPS di lembaga perbankan menduduki posisi yang kuat karena keberadaannya sangat penting dan strategis. Berdasarkan Peraturan Bank Indonesia (PBI) No 11/03/PBI/2009 tentang Bank Umum Syariah, DPS selain mengawasi salah satu lembaga keuangan syariah, anggota DPS dapat merangkap jabatan di empat lembaga keuangan syariah lain. Selain bisa merangkap jabatan secara horizontal di beberapa lembaga keuangan syariah, DPS juga bisa merangkap secara vertikal, yakni dengan merangkap jabatan sebagai DSN dan konsultan keuangan sekaligus. Hal ini disamping akan menimbulkan konflik kepentingan (conflict of interest) antara lembaga keuangan satu dengan yang lain, juga mengakibatkan ketidaknetralan dalam memberikan keputusan atau fatwa. Maka dari itu seyogianya DPS hanya boleh menjabat di satu lembaga keuangan saja. Pengawasan perbankan syariah pada dasar- nya memiliki sistem pengawasan dari aspek keuangan, kepatuhan pada perbakan secara umum dan prinsip kehati- hatian bank serta pengawasan prinsip syariah dalam kegiatan operasional bank. Ketentuan pengawasan merupakan bagian dari ketentuan operasional bank yang menjadi benteng perlindungan publik agar pegawai bank, pengurus bank dan pihak terafiliasi mentaati berbagai ketentuan kehati-hatian yang telah dite- tapkan sehingga apabila terdapat pelanggaran maka dalam rangka melaksanakan pengawasan, otoritas pengawas akan mengenakan sanksi.

2. Tinjauan Kelembagaan DPS berdasarkan Remunerasi

Remunerasi yang diterima oleh DPS diatur dalam Peraturan Otoritas Jasa Keuangan (POJK) Nomor 59/POJK.03/2017 Tahun 2017 tentang Penerapan Tata Kelola dalam Pemberian Remunerasi bagi Bank Umum Syariah dan Unit Usaha Syariah (POJK 59/2017). Remunerasi didefinisikan dalam pasal 1 ayat 7 POJK 59/2017, yang menyatakan bahwa remunerasi adalah imbalan yang ditetapkan dan diberikan 
Tinjauan Kelembagaan Dewan Pengawas Syariah dari Aspek Nomenklatur, Kedudukan di Lembaga Perbankan dan Remunerasi

kepada anggota direksi, anggota dewan komisaris, anggota DPS, dan/atau pegawai baik yang bersifat tetap maupun variabel dalam bentuk tunai maupun tidak tunai sesuai dengan tugas, wewenang, dan tanggung jawabnya. Lebih lanjut, pasal 3 POJK 59/2017 menyatakan bahwa bank wajib memiliki kebijakan remunerasi secara tertulis bagi direksi, dewan komisaris, DPS, dan pegawai. Dan dalam pasal 4 POJK 59/2017 dijelaskan bahwa direksi wajib menyusun kebijakan remunerasi sebagaimana dimaksud dalam Pasal 3.

Menurut peraturan di atas bisa diambil kesimpulan bahwa yang menentukan remunerasi DPS adalah direksi lembaga keuangan syariah. Sedangkan direksi dalam hal ini juga termasuk ke dalam pihak yang diberikan nasihat dan diawasi oleh DPS. Hal ini akan menimbulkan ketidakobjektifan dalam pelaksanaan tugas karena pasti akan berat sebelah dalam mengambil keputusan. Seharusnya yang menentukan dan memberikan remunerasi kepada DPS adalah asosiasi lembaga keuangan syariah seperti Asosiasi Bank Syariah Indonesia (ASBISINDO), Asosiasi BMT Seluruh Indonesia (ABSINDO), dan lain-lain.

\section{KESIMPULAN}

Mengingat aspek pengawasan terhadap lembaga ekonomi dan lembaga keuangan syariah memiliki kekhasan tersendiri, yaitu meliputi aspek keuangan dan administrasi di satu sisi, dan aspek penerapan syariah di sisi yang lain, maka pengawasan terhadap lembaga-lembaga keuangan yang berlabelkan syariah harus lebih ketat. Maka dari itu DPS harus menjadi lembaga yang independen, memiliki kekuatan hukum yang pasti dan tidak tergantung kepada lembaga lainnya, sehingga peranan dan fungsinya terhadap lembaga keuangan syariah benar-benar sesuai dengan ajaran Islam. Tugas utama DPS sebagaimana dijelaskan dalam Pasal 32 UU Perbankan Syariah adalah memberikan nasihat dan saran kepada direksi serta mengawasi kegiatan bank agar sesuai dengan prinsip syariah. Maka dari itu, nomenklatur DPS di Indonesia akan lebih tepat jika disebut sebagai Dewan Penasihat Syariah (Sharia Advisory Board), bukan Dewan Pengawas Syariah (Sharia Supervisory Board). DPS idealnya hanya boleh menjabat di satu lembaga keuangan saja. hal ini untuk menghindari konflik kepentingan (conflict of interest) antara lembaga keuangan satu dengan yang lain dan ketidaknetralan dalam memberikan keputusan atau fatwa. Seharusnya yang menentukan remunerasi DPS bukan direksi lembaga keuangan syariah, tetapi asosiasi lembaga keuangan syariah. Hal ini untuk menghindari ketidakobjektifan dalam pelaksanaan tugas karena direksi juga termasuk ke dalam pihak yang diberikan nasihat dan diawasi oleh DPS. 


\section{DAFTAR PUSTAKA}

Absor, C., Hana, K. F., \& Nur, F. R. (2019). Ada Apa dengan Dewan Pengawas Syariah di Koperasi Simpan Pinjam dan Pembiayaan Syariah? MALIA: Journal of Islamic Banking and Finance, 3(2), 155-173.

Antonio, S. (2001). Bank Syariah: Dari Teori ke Praktik. Jakarta: Gema Insani. Arifin, Z. (2006). Dasar-dasar Manajemen Bank Syariah. Jakarta: Pustaka Alvabet.

Briefcase Book Edukasi Profesional Syariah. (2005). Sistem dan Mekanisme Pengawasan Syariah. Jakarta: Renaisan.

Djazuli. A., \& Janwari, Y. (2002). Lembaga-lembaga Perekonomian Umat, Jakarta: Raja Grafindo Persada.

Hamoud, S. (1985). Islamic Banking, London: Arabian Information Ltd.

Haron, S. (1996). Prinsip dan Operasi Perbankan Islam, Kuala Lumpur: Berita Publishing Sdn. Bhd.

Ismail. (2011). Perbankan Syariah, Jakarta: Kencana Prenada Media Group. Machmud, A., \& Rukmana, H. (2010). Bank Syariah: Teori, Kebijakan, dan Studi Empiris di Indonesia, Jakarta: Erlangga.

Misbach, I. (2012). Kualitas Layanan Bank Syariah, Makassar: Alauddin Press.

Mubarok, J. (2004). Perkembangan Fatwa Ekonomi Syariah, Bandung: Pustaka Bani Quraisy.

Perwataatmadja, K., \& Antonio, S. (1992). Apa dan Bagaimana Bank Islam, Yogyakarta: Dana Bhakti Wakaf.

Prasetyoningrum, Ari Kristin. (2009). Analisis Pengaruh Independensi dan Profesionalisme Dewan Pengawas Syariah terhadap Kinerja Bank Perkreditan Rakyat Syariah di Jawa Tengah. Jurnal Ekonomi Islam Fakultas Syariah IAIN Walisongo Vol 12(1).

Rhanu. (2010). Tantangan dalam Pengembangan Perbankan Syariah di Indonesia, Jakarta: Gunadarma.

Said, S. (2015). Sharia Banking Performance in Makassar. Al-Ulum: Jurnal Studi Islam Vol 15(1). 21-42.

SK DSN No. 03 Tahun 2000 tentang Petunjuk Pelaksanaan Penetapan Anggota DPS pada Lembaga Keuangan Syariah.

Syariati, A., \& Syariati, Namla Elfa. (2012). Islamic Bank as Bank of Ethics. In Proceeding of Annual South East Asian International Seminar.

Thomas, S. (2001), Kelembagaan Perbankan, edisi kedua, Jakarta: Gramedia Pustaka Utama.

Tim Pengembangan Perbankan Syariah Institut Bankir Indonesia. (2002). Konsep, Produk dan Implementasi Operasional Bank Syariah, Jakarta: Djambatan.

Undang-undang Perbankan No. 14 tahun 1998, edisi pertama, cetakan pertama, Jakarta: Rajawali Pers. 
Tinjauan Kelembagaan Dewan Pengawas Syariah dari Aspek Nomenklatur, Kedudukan di Lembaga Perbankan dan Remunerasi

Wardani, N. (2008). Analisis Potensi dan Preferensi Masyarakat terhadap Bank Syariah di Wilayah Kota Medan, Jurnal Plan: Penelitian Ilmu Manajemen dan Bisnis Vol 3(1). 46-54.

Warkum, S. (1996). Asas-asas Perbankan Islam dan Lembaga-lembaga Terkait (BAMUI \& Takaful), Jakarta: Rajawali Pers.

Widyanto, Eko Adi. (2010). Peran Independensi Dewan Pengawas Syariah terhadap Loyalitas Penerapan Syariat Islam. Jurnal Eksis Vol 6(2). 1440-1605. 